This work has as aims the treatment about the production (elaboration) of a research diary, and goes on in the sense of presenting the example of experience with images, denying the illustrative character of those images. Through the registered visualities in the research instruments we focus the non-verbal meanings which can show new ways to approach to clear comprehension about a cultural and aesthetic vision.

Keywords: Research diary, visualities, aesthetic learning. 


\section{Entre textos e imagens: virações de um diário de pesquisa}

\section{Leda \\ GUIMARÃES}

Wolney Fernandes de OLIVEIRA

Este trabalho tem como objetivo tratar a construção de um diário de pesquisa, e avança no sentido de apresentar exemplo de experiência com imagens, refutando o caráter meramente ilustrativo das mesmas. Através das visualidades registradas no instrumento de pesquisa procura-se significados não verbais que descortinem novos caminhos de aproximação para a compreensão de uma visão estética e cultural.

Palavras-chave: Diário de pesquisa, visualidades, aprendizagem estética. 
Esta reflexão nasceu de uma experimentação com diário de campo, desenvolvida no final da minha graduação em Artes Visuais/Design Gráfico em 2003 e continuada no Programa de Pós-Graduação em Cultura Visual em 2007 pela Universidade Federal de Goiás. O Diário de Pesquisa Visual (DPV), como o instrumento foi batizado, permitiu reunir idéias, conceitos, exemplos e experiências utilizando para tanto, a linguagem visual. Desenhos, recortes, fotografias, cores e texturas formam o corpo do diário e permitem construir e reconstruir, num contexto relacional, percepções e novas significações sobre o tema levantado em minha pesquisa no mestrado.

As reflexões realizadas têm como cenário a preocupação com aspectos metodológicos da pesquisa em arte, cuja dimensão epistemológica é definidora de sua própria identidade. Nessa perspectiva, a documentação, o registro e sua conseqüente articulação de sentidos não podem ser negligenciados no contexto do exercício acadêmico, considerando a sua relevância para o processo de conhecimento e sistematização do saber e do fazer.

Para Lewgoy e Arruda (2004, p. 123-124), o diário consiste em um instrumento capaz de possibilitar "o exercício acadêmico na busca da identidade profissional" à medida que, através de distanciamentos e aproximações sucessivas, pode-se realizar uma "reflexão da ação cotidiana, revendo seus limites e desafios".

Meu Trabalho de Conclusão de Curso (TCC) da graduação: "A Rainha do Mundo e a Serpente do Rio - Imaginário e oralidade popular no contexto do livro infantil" consistiu no recolhimento e análise de diferentes narrativas sobre Santa Dica. Líder religiosa e política, uma mulher à frente do seu tempo, ela foi a única expressão em Goiás de movimento messiânico, ocorrido em várias regiões do Brasil. Muitas são as histórias contadas a respeito desta mulher e elas ainda fascinam pelo tom maraviIhoso e fantástico que os moradores da pequena Lagolândia ${ }^{1}$ dão a estas narrativas. Procurei recompor e reconstruir, imageticamente, o universo daquela oralidade. Minha tarefa foi localizar naquelas cenas narrativas a percepção e produção de uma estética e extrair delas uma proposta visual adequada ao 
projeto de livro infantil.

O deslocamento de minha pesquisa para o mestrado transferiu-me para um terreno movediço onde apenas os aspectos formais relacionados à imagem não seriam suficientes para a discussão que a Cultura Visual trazia. O lugar da experiência (VAN MANEN, 2003) na relação entre a imagem e o indivíduo começou a revelar substratos mais complexos e variáveis, uma vez que as imagens não vêm desprovidas de um contexto. Elas trazem referências culturais que por sua vez, também estão associadas a outras imagens tecendo uma rede de significados e de múltiplas realidades.

A Cultura visual estuda e investiga a imagem como via de acesso ao conhecimento, como experiência que realça "realidades que de outro modo passariam despercebidas". (BUCK-MORSS, 2005, apud MARTINS, 2007, p. 13).

As interpretações visuais, por sua vez, têm uma cultura, as quais afetam tanto o processo de produção como o de recepção. Construídas a partir de um repertório cultural, tecido no passado, as imagens fixam e difundem modos de compreensão do mundo no presente. (NASCIMENTO, 2006).

Estas idéias foram importantes para compreender aspectos da relação entre imagem e a prática social. Ou seja, o que está em jogo não são as imagens pelas imagens, mas a experiência que as pessoas fazem delas. Estas concepções reposicionaram também o meu DPV. Visto anteriormente apenas como um exercício formal dentro da minha prática como ilustrador, agora, este instrumento metodológico se reveste com as cores da minha própria experiência em torno do imaginário da cidade onde Santa Dica viveu, não por acaso, também minha cidade-natal.

Este texto parte, portanto, de um referencial conceitual que permite discutir a construção do DPV e avança no sentido de apresentar exemplo de experiência com imagens, refutando o caráter meramente ilustrativo as mesmas. Através das visualidades registradas no DPV procuro significados não verbais que descortinem novos caminhos de aproximação para a compreensão de uma visão estética e cultural. 


\section{Imagens que viram escrita}

O privilégio da "palavra escrita" como a mais sofisticada forma de desenvolvimento intelectual acabou fadando as representações visuais a uma escala menor de importância na cultura ocidental. Sob esta perspectiva, o saber é encarado somente como depósito enciclopédico, na medida em que ele ocupa apenas um ponto fixo ficando encapsulado nos discursos de autoridade acadêmica. Os postulados desta autoridade estão sempre atrelados a um conceito positivista de cientificidade. Ou seja, trazem embutidos em suas proposições o paradigma tradicional do texto escrito como única fonte geradora de conhecimento, domesticando e orientando o olhar de quem faz pelos paradigmas teóricos.

A visão contemporânea não se encontra mais impregnada apenas por sentimentos racionalistas e funcionalistas. Os tempos são outros e frente às variadas realidades vem desenvolvendo-se um novo jeito complexo de olhar onde não parecem caber mais definições e classificações dominantes. Tudo é relativizado em um movimento que abre várias possibilidades de leitura dos fenômenos sociais que se multiplicam (LEITE, 1995).

A entrada em cena da Cultura Visual reconfigura o papel das imagens no mundo contemporâneo. Realidade, hoje, "é inseparável das imagens e da ficção" (MARTINS, 2006, p. 6) uma vez que o mundo é fruto de variadas interpretações. Entender as imagens como uma elaboração complexa de sentidos propõe deslocamentos de conceitos que não obedecem a uma estrutura de causa-efeito. Sob a perspectiva da Cultura Visual, estamos sempre em trânsito nas práticas do ver.

Essa perspectiva fragilizou os cânones do design gráfico que eu trazia da minha experiência na graduação que sempre privilegiou a unidade e a identidade em detrimento dos olhares e atitudes auto-expressivas e intuitivas. Ao questionar os regimes formais da minha prática profissional, a transitoriedade do papel que as imagens exercem na sociedade atual, mostrou-me que direcionamentos objetivos ou um posicionamento neutro, impessoal não caberiam mais na minha prática como pesquisador.

Mesmo que o ponto de partida seja meu próprio contex- 
to é preciso dialogar com os diferentes papéis de atuação em contextos diferenciados. Uma alternância contínua de posições que vai descortinando, revelando contextos variados e (re)construções da realidade. Se nossas visões de realidade devem ser mais inclusivas, então precisamos ter uma perspectiva mais ampla sobre outras maneiras de articulação de sentidos e elaboração de discursos.

Nesta tentativa, lanço mão das imagens em meu DPV como instrumentos capazes de reivindicar o direito de usar uma linguagem multifacetada e criar caminhos para um possível entendimento ou estranhamento, articulando conteúdos internos e externos. Assim, elas mostram-se como ferramentas de construção de fazeres e saberes que pressupõe não apenas um acesso obrigatório, único e linear, mas sim uma gama de direções e vertentes que mapeiam múltiplas possibilidades que ampliam o horizonte numa rede complexa de relações.

De acordo com Hernández, ao alargar o sentido de alfabetização visual, é necessário "adquirir novas linguagens que forneçam acesso a novas formas de trabalho e de práticas cívicas e privadas" (HERNÁNDEZ, 2006, p. 7) para a construção de um aprendizado social mais amplo. A experiência visual e o exercício com imagens contribuem no pensar crítico, pois também pressupõem um jogo de seleção, associação e reconstrução. Essa idéia alinha-se à abordagem emancipatória e libertadora da pedagogia crítica segundo Paulo Freire entendendo que, através das visualidades também somos estimulados a desenvolver o intelecto e a imaginação para nos apropriarmos de nossas próprias histórias.

O aspecto da visualidade que se refere a como nós olhamos o mundo, tem sido relevante para a construção da representação do conhecimento. Minha história, permeada por um contato muito próximo com o mundo das imagens, reconsiderou minha prática profissional como designer gráfico e ilustrador trazendo questões relevantes para meu cotidiano: Como representar, sob o rigor acadêmico, esse conhecimento que é essencialmente imagético? Que tipo de escrita propõe uma coerente apresentação das novas formas de ver e fazer? "Por que as imagens apenas aparecem nas monografias como ilustrações? 
Por que elas não são o texto?" (BELIDSON DIAS, 2007). Como transformar a linguagem das visualidades numa linguagem etnográfica?

Nesta pesquisa, ao ampliar as noções de um diário de campo foi possível compreendê-lo como instrumento que carrega não apenas reproduções de imagens, mas conteúdos visuais que realçam um tipo de subjetividade que se conecta a uma visão plural e necessária onde não se separa o conteúdo da forma.

\section{Rio que vira serpente}

Meu DPV consiste em um pequeno livro de capa dura, encontrado em uma dessas lojas de livros usados que já foi manuseado e marcado pelo tempo. Os registros visuais são feitos em cima do texto já impresso no livro. Na época, o que era apenas uma maneira de se "fazer diferente", hoje se reveste de novo sentido. Imagem e escrita se fundem para refutar os paradigmas binários, que opõem objetividade e subjetividade, textos e imagens, popular e erudito, como se essas dicotomias dessem conta de dois universos incompatíveis, quando, na realidade fazem parte de uma mesma esfera.

O exemplo que trago para esta reflexão necessita de uma contextualização que nasce a partir de uma das narrativas por mim recolhidas em Lagolândia. O vilarejo é uma destas cidadezinhas com Igreja, praça na frente, casas em volta da praça, não mais que 300 habitantes e um rio que contorna toda a área urbana. Graças, em grande medida, ao fato de ter sido pouco afetada pelo "progresso", a cidadela é um daqueles raros lugares que preserva muitos dos seus ritos e práticas culturais. Dentre tantas estórias contadas na região, uma das mais evidentes nas narrativas do imaginário da cidadela é a serpente do rio.

Não há morador da região que não conheça uma versão da história da serpente. A minha, fruto da junção de vários discursos ouvidos ao longo da infância, resumidamente conta que, acuada pelos guardas que cercaram a cidadela a mando do governo do Estado, Dica convoca o povo para a travessia 
das águas do Rio do Peixe. Ela, então chama a serpente que vivia enrolada no morro da Igrejinha e com três fios de cabelos amarra a cobra na curva do rio para dar conta dos inimigos. Desde então, o bicho continua preso no fundo das águas, agora por apenas um fio que ao arrebentar selará o fim da cidade

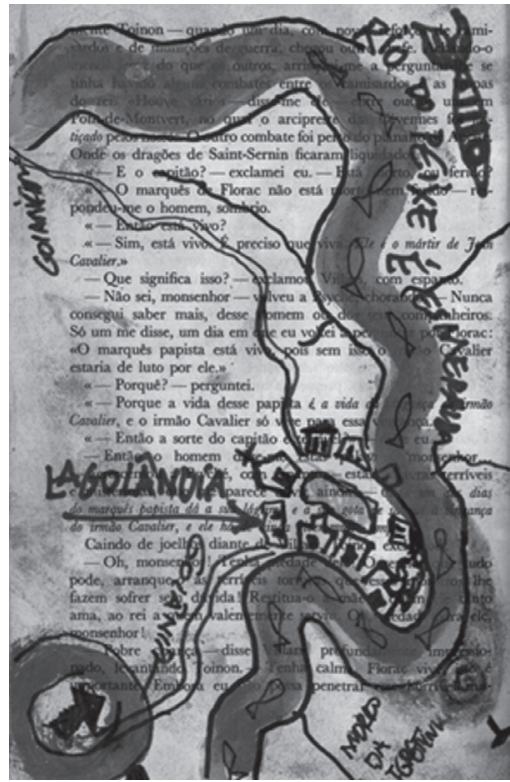

Figura 1: Desenho do Rio do Peixe e do mundo.

Numa fase exploratória da pesquisa, com ajuda de um mapa e segundo minhas próprias percepções da geografia local, registrei em meu diário a localização da cidade e conseqüentemente o traçado que o rio faz na região (Figura 1).

Á medida que a pesquisa avançava e a história da serpente foi se sobressaindo entre tantas outras imagens desenhadas pelas narrativas, comecei a reunir, em meu diário, várias representações de serpentes de fontes variadas tentando responder às questões: O que caracteriza e diferencia a imagem da serpente que a Dica amarrou no fundo do rio destas outras cobras? Que elementos visuais (linguagem, traçado, cores, forma,...) devo agrupar para a concepção de uma representação gráfica que reflita aspectos da-

quela alegoria?

As respostas a estas perguntas foram dadas á medida que alguns aspectos do dia-a-dia da cidade foram incorporados na concepção da imagem da serpente. As fitas coloridas das festas religiosas, detalhes da arquitetura e o movimento das águas compunham o desenho que serviria como rascunho final para a ilustração do livro (Figura 2).

Convidado a revisitar meu DPV já no período do Mestrado, "reli" as imagens buscando novas evidências, criando relações, buscando sentidos. Foi assim que aspectos da figura 1 e da figura 2 foram atribuindo significados diferentes a um fenômeno que já me soava familiar. Como em uma espécie de ato de reconhecimento, olhando o desenho do traçado do rio e o 


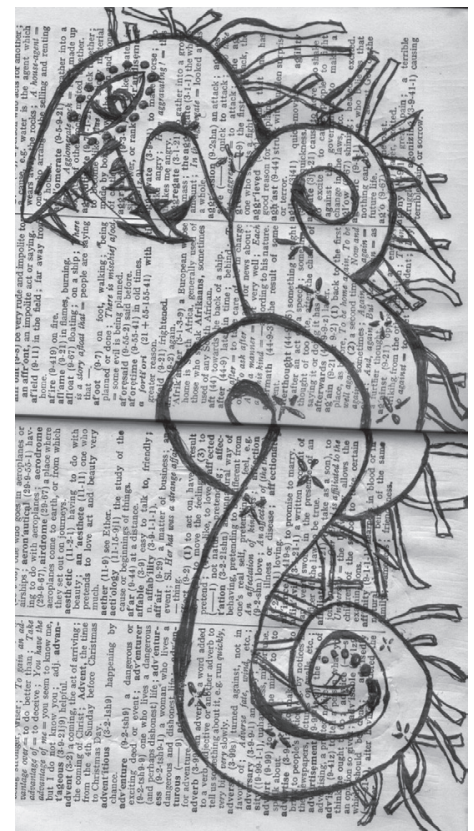

Figura 2: Desenho da Serpente do Rio

rascunho da cobra, concluí: O rio é a serpente!

A partir desta conclusão fui impelido a me perguntar sobre a importância do rio para a região. Naquela época e ainda hoje, o rio sempre exerceu importante papel no movimento tecido cotidianamente pela cidade. O banho nas águas correntes feito todas as tardes por adultos e crianças, as constantes lavagens de roupa e vasilhas e as idas e vindas para buscar água limpa para beber revelam uma intensa relação com o Rio do Peixe que, como a serpente, cuida da cidade e a mantém viva. Uma fala de Edleuza Alves, moradora do vilarejo, ao contar a lenda da serpente, ajudou-me também a confirmar: A madrinha Dica fez muitas coisas. Ela amarrou uma serpente no rio com trs fios de cabelo e disse que no fim dos tempos, quando o Itimo fio de cabelo arrebentar, o povo s vai viver se pegar gua da boca da serpente. Dizem que dois fios $j$ arrebentaram, $s$ resta um. E o rio est secando. Eu me lembro que no Vau no dava $p$. Todo mundo tinha que atravessar de canoa e hoje a gente enxerga o fundo com esse tiquinho dgua.

Os cruzamentos feitos entre as duas imagens oferecem, em suma, um desdobramento reflexivo atribuído ao DPV, pois apresenta novos pontos de vista, idéias e concepções. A partir do intercâmbio das imagens é possível elaborar outras leituras da realidade. O impacto desta experiência alude ao poder de certas representações visuais despertarem reflexões críticas.

O convite que a experiência deixa é de não nos contentarmos apenas vendo as imagens como constatação argumentativa, mas viajando nelas com o texto e para além do texto. As imagens podem (...) estar presentes no texto para criar ilusões e/ou alusões, 
acordos e/ou desacordos, dúvidas e nunca certezas (GARCIA, 2005, p. 48).

As imagens, neste caso, abrem espaço e assumem uma posição que estimula o pensar, possibilitando um modo reflexivo de interação. Mostram contextos além daqueles que aparecem na superfície que um texto descreve e analisa.

Portanto, o registro visual em meu diário também significou realizar análise que, de acordo com Mioto (2001), "consiste no exame minucioso dos dados obtidos no momento anterior, com o objetivo de sistematizar aspectos relacionados à situação estudada visando compreender a situação da maneira mais abrangente e articulada possível". É um primeiro passo para avançar na explicação e compreensão da totalidade do fenômeno em seu contexto, captando seu dinamismo e suas relações.

É possível exercitar a reflexão, a partir do lugar que se ocupa. Não há produção de conhecimento que não se enraíze no seu produtor, e esse produtor está situado, quer dizer, pertence a um contexto. Meu contexto é o das imagens e é com elas e a partir delas, que sigo interpretando o mundo.

\section{Nota}

1.O Distrito de Lagolândia está localizado no município de Pirenópolis, distante deste $37 \mathrm{~km}$. Situado na microrregião Centro-norte ou Planalto. Pirenópolis ocupa uma área de 182 km2. Limita-se com o municípios de Goianésia e Vila Propício ao Norte, Jaraguá São Francisco e Petrolina à Oeste, Anápolis ao Sul e Abadiânia, Corumbá e Cocalzinho à Leste. Está distante 120 km de Goiânia, capital do Estado de Goiás. (Fonte: IBGE).

\section{Referências}

AZEVEDO, R. Como o ar não tem cor, se o céu é azul? Vestgios dos contos populares na literatura infantil. São Paulo. Universidade de São Paulo, 1998 (Dissertação de mestrado).

BUCK-MORSS, S. apud MARTINS, R. A cultura visual e a construção social da arte, da imagem e das práticas do ver. In: Marilda Oliveira de Oliveira (Org.). Arte, Educao e Cultura. Santa Maria: Editora UFSM, p.19 a 40.

DIAS, B. A escrita acadmica. Universidade de Brasília. Trabalho não publicado.

GARCIA, A. Imagens: ilusão, alusão, provocação, inspiração... são... In: 
OLIVEIRA, Inês Barbosa de, ALVES, Nilda e BARRETO, Raquel Goulart (Orgs.). Pesquisa em Educao Mtodos, temas e linguagens. Rio de Janeiro: DP\&A, 2005, p.39-50.

HERNÁNDES, F. From Visual Literacy to Visual Culture Literacy. In: Interdisciplinary Dialogues in Arts Education. International InSEA Congress, Viseu, Portugal, 2006, 14p. Trabalho não publicado.

LEITE, J. S. Para Alm do Moderno. In: Estudos em Design, v. 3, n. 1, p. 109-121, jul. 1995.

LEWGOY, A. M. B.; ARRUDA, M. P. Novas tecnologias na prtica profissional do professor universitrio: a experincia do dirio digital. Revista Textos e Contextos: coletâneas em ServiçoSocial, Porto Alegre: EDIPUCRS, n. 2. 2004, p. 115-130.

MARTINS, R. Cultura Visual: imagem, subjetividade e cotidiano. Disponível em: http://www.corpos.org/anpap/2004/textos/ceaa/RaimundoMartins.pdf. Acesso em: 30 set. 2007.

Sobre textos e contextos da Cultura Visual. Visualidades: Revista do Programa de Mestrado em Cultura Visual. Goiânia, v. 4, n. 1 e 2, p. 5-11, jan./jun., jul./dez. 2006.

MIOTO, R. C. T. A percia social: proposta de um percurso operativo. Serviço Social e Sociedade, São Paulo, Cortez Editora, n. 67, 2001, p. 145-158.

NASCIMENTO, E. A. A Cultura Visual no Ensino de Arte Contempornea: singularidades no trabalho com as imagens. Disponível em: http://www. artenaescola.org.br/pesquise_artigos_texto.php?id_m=50. Acesso em: 02 mar. 2008.

SILVA, A. L.; GOMES, T. L.; OLIVEIRA, W. F. A Rainha do Mundo e a Serpente do Rio. 2003. 124 f. TCC - Trabalho de Conclusão de Curso (Graduação em Artes Visuais) - Faculdade de Artes Visuais, Universidade Federal de Goiás, Goiânia, 2003.

VAN MANEN, M. La reflexión fenomenológica hermenéutica. In: Investigacin educativa y experiencia vivida. Ciencia humana para una pedagogía de la acción y la sensibilidad. Barcelona: Idea Books, 2003. 


\section{LEDA GUIMARÃES}

Doutora em Artes pela Escola de Comunicação e Artes - ECA da USP. Mestre em Educação e Linguagens pela UFPI. Professora da Faculdade de Artes Visuais da UFG. Atua na Licenciatura e no Mestrado em Cultura Visual. Email: ledafav@yahoo.com.br

\section{WOLNEY FERNANDES DE OLIVEIRA}

Graduado em Artes Visuais com habilitação em Design Gráfico pela Universidade Federal de Goiás (2003). Atualmente é aluno bolsista pela CAPES do Programa de Pós Graduação em Cultura Visual da UFG.

Email:wolney.fernandes@yahoo.com.br 